\title{
RELATIONSHIPS BETWEEN FETAL WEIGHT, PLACENTAL WEIGHT AND MATERNAL PLACENTAL CIRCULATION IN THE RABBIT AT DIFFERENT STAGES OF GESTATION
}

\author{
N. W. BRUCE AND R. W. ABDUL-KARIM* \\ The Nuffield Institute for Medical Research, \\ University of Oxford, Osler Road, Headington, Oxford OX3 9DS
}

(Received 10th December 1971)

\begin{abstract}
Summary. Fetal weights, placental weights, myometrial, vaginal and maternal placental blood flows (estimated with radioactive microspheres) were measured in forty-one rabbits at 16, 20, 24 or 28 days of gestation; term occurs around Day 31. Multiple linear regression analysis indicated that fetal weight and placental weight were positively related at all stages of gestation examined. Fetal weight and placental blood flow were negatively related at Day 16 , but positively related at Days 20, 24 and 28. The conceptus adjacent to the ovary had greater placental weight and flow values than the means from all conceptuses in the horn by Day 20 but fetal weight was only greater by Day 28 . The relevance of these findings to the determination of fetal weight is discussed.
\end{abstract}

\section{INTRODUGTION}

In the pregnant rabbit near term, fetal weight is positively related to placental weight and to the rate of maternal blood flow through the placenta (Duncan, 1969). These relationships may have causal origins or they may be due to other factors, such as the genotype of the conceptus or the position of the conceptus in the uterine horn, acting similarly on the related parameters.

These possibilities were investigated by examining fetal weight, placental weight and maternal placental circulation relationships from Day 16 to Day 28 of gestation; term in the rabbit occurs around Day 31 . The influence of position in the uterine horn was also examined and data were obtained on weight and circulation changes in other reproductive organs.

\section{MATERIALS AND METHODS}

Forty-one rabbits which were of the New Zealand White or Chinchilla breeds were mated at approximately mid-day; the following day was called Day 1 of

* Permanent address: Department of Obstetrics and Gynecology, State University of New York, Upstate Medical Center, Syracuse, New York, U.S.A. 
gestation. On Day 16, 20, 24 or 28, each rabbit was anaesthetized with sodium pentobarbitone (Veterinary Nembutal; Abbott's Laboratories) $30 \mathrm{mg} / \mathrm{kg}$ intravenously, supplemented with ether as necessary. Blood flow was measured with radioactive microspheres; in general, the procedures described by Duncan (1969) were followed. The left ventricle was catheterized for injection of microspheres and the left femoral artery was catheterized to monitor arterial pressure. The right femoral artery in all rabbits and the left brachial artery in thirteen rabbits were catheterized for blood withdrawal to determine cardiac output. The rabbit was placed in a supine position and, when its depth of anaesthesia and arterial blood pressure were stable, a blood sample was taken for $\mathrm{pH}, \mathrm{PO}_{2}$ and $\mathrm{PCO}_{2}$ measurements. An injection syringe containing approximately 200,000 microspheres (Minnesota Mining and Manufacturing Co.) of $15 \pm 5 \mu \mathrm{m}$ diameter labelled with 46 scandium (Sc), 51 chromium $(\mathrm{Cr}$ ) or 85 strontium ( $\mathrm{Sr}$ ) and suspended in a dextran saline solution, was connected directly to the ventricular catheter and continuously agitated to maintain an even dispersion of microspheres within the syringe. Withdrawal of blood from the femoral and, when catheterized, the brachial artery was started at a steady rate of $5 \mathrm{ml} / \mathrm{min} ; 10 \mathrm{sec}$ later, the suspension of microspheres was slowly injected into the left ventricle over a period of $30 \mathrm{sec}$. Blood withdrawal was continued throughout the injection period and for a further $20 \mathrm{sec}$ : the animal was then killed with an overdose of sodium pentobarbitone.

Radioactivities of the whole carcass, blood samples, heart, lung, kidneys and other major organs were measured with a whole body counter designed by P. Johnson and A. T. Warner and validated (P. Johnson, unpublished data) at the Nuffield Institute for Medical Research. This counter provides radioactivity measurements substantially free from errors due to the geometry of the counting conditions and to the distribution of the isotope within the sample. Small and large samples can be directly compared after correction for self absorption. Smaller samples, such as the placenta and vagina, were measured in an automatic well-type scintillation counter (Nuclear Enterprises Ltd). The efficiency of the well-counter was greater but count rate fell as the height of the sample within the well increased. Except for the myometrium sample, heights were kept within 1 to $2 \mathrm{~cm}$ from the bottom of the well; under these conditions, maximum variation due to height after reference to a standard sample approximately $1.5 \mathrm{~cm}$ in height was less than $5 \%$. Samples of myometrium ranged from approximately 2.5 to $3.5 \mathrm{~cm}$ in height and count rates were increased by $15 \%$ to compensate for the reduction in counting efficiency.

Sufficient microspheres were injected to ensure that the radioactivity of every organ examined was several times the background count. The standard deviation of repeated counts of an organ receiving a high percentage of the cardiac output such as the kidney was about $1 \%$, while that for organs receiving the smallest percentage of cardiac output measured was about $7 \%$. Weights and radioactivities of major organs were measured after the surrounding fat had been removed. Placentae and adjacent maternal decidua were dissected separately, placental membranes and fluids were removed as uniformly as possible and the placentae and decidua were placed individually in hermetically sealed vials. They were weighed to the nearest milligram and measured for 
radioactivity. The 16- and 20-day fetuses were weighed similarly, and 24- and 28-day fetuses were weighed directly to the nearest $0.1 \mathrm{~g}$. Dead and resorbed fetuses were recorded as implantation sites (Table 1) but excluded from the remainder of the results.

Cardiac output $(\mathrm{ml} / \mathrm{min}$ ) was calculated by dividing the radioactivity of the whole carcass by the radioactivity of the femoral arterial blood sample and multiplying by 5 . The percentage of the cardiac output distributed to each organ was calculated by expressing the organ radioactivity as a percentage of the whole-carcass radioactivity. The absolute flow $(\mathrm{ml} / \mathrm{min})$ to each organ was calculated by multiplying the latter percentage by the estimated cardiac output.

A multiple linear regression analysis was used to examine the relationship of fetal weight $(\mathrm{Y})$ to placental weight $\left(\mathrm{X}_{1}\right)$ and maternal placental blood flow

Table 1. Observations on pregnant rabbits

\begin{tabular}{|c|c|c|c|c|}
\hline & \multicolumn{4}{|c|}{ Stage of gestation in days } \\
\hline & 16 & 20 & 24 & 28 \\
\hline $\begin{array}{l}\text { No. in group } \\
\text { Maternal weight }(\mathrm{g}) \\
\text { Cardiac output }(\mathrm{ml} / \mathrm{min}) \\
\text { Arterial pressure } \\
\quad \text { (mm } \mathrm{Hg}) \\
\text { Arterial } \mathrm{PO}_{2}(\mathrm{~mm} \mathrm{Hg}) \\
\text { Arterial } \mathrm{PCO}_{2}(\mathrm{~mm} \mathrm{Hg}) \\
\text { Arterial pH } \\
\text { No. of implants } \\
\text { No. of live fetuses } \\
\text { Myometrial weight (g) } \\
\text { Myometrial blood flow } \\
\text { (ml/min) } \\
\text { Vaginal weight (g) } \\
\text { Vaginal blood flow } \\
\text { (ml/min) }\end{array}$ & $\begin{array}{c}18 \\
3565 \pm 123 \\
501 \pm 32 \\
98 \pm 3 \cdot 5 \\
77 \pm 2 \cdot 9(14) \\
34 \pm 0 \cdot 9(14) \\
7 \cdot 43 \pm 0.01(14) \\
8 \cdot 9 \pm 0 \cdot 7 \\
8 \cdot 3 \pm 0.7 \\
38 \cdot 7 \pm 2 \cdot 5 \\
9 \cdot 61 \pm 0.92 \\
2 \cdot 57 \pm 0.17 \\
0.83 \pm 0 \cdot 11\end{array}$ & \begin{tabular}{|c}
13 \\
$3465 \pm 125$ \\
$496 \pm 31$ \\
\\
$97 \pm 3 \cdot 7$ \\
$82 \pm 4 \cdot 5(8)$ \\
$35 \pm 3 \cdot 4(7)$ \\
$7 \cdot 38 \pm 0 \cdot 03(8)$ \\
$8 \cdot 6 \pm 1 \cdot 0$ \\
$8 \cdot 4 \pm 1 \cdot 1$ \\
$49 \cdot 1 \pm 4 \cdot 8$ \\
\\
$11 \cdot 61 \pm 1 \cdot 10(10)$ \\
$4 \cdot 16 \pm 0 \cdot 19$ \\
$1 \cdot 72 \pm 0 \cdot 21$
\end{tabular} & $\begin{array}{c}5 \\
3645 \pm 219 \\
461 \pm 94 \\
84 \pm 10 \cdot 5 \\
79 \pm 4 \cdot 4(4) \\
35 \pm 1 \cdot 0(4) \\
7 \cdot 38 \pm 0 \cdot 04(4) \\
8 \cdot 6 \pm 0 \cdot 5 \\
8 \cdot 6 \pm 0 \cdot 5 \\
41 \cdot 8 \pm 1 \cdot 2 \\
5 \cdot 29 \pm 1 \cdot 06 \\
5 \cdot 68 \pm 0 \cdot 92 \\
1 \cdot 36 \pm 1 \cdot 10\end{array}$ & $\begin{array}{c}5 \\
3782 \pm 231 \\
520 \pm 59 \\
103 \pm 8 \cdot 3 \\
87 \pm 2 \cdot 8 \\
34 \pm 2 \cdot 7 \\
7 \cdot 42 \pm 0 \cdot 03(5) \\
8 \cdot 4 \pm 0 \cdot 7 \\
8 \cdot 2 \pm 0 \cdot 8 \\
46 \cdot 8 \pm 7 \cdot 4 \\
5 \cdot 53 \pm 0.91(4) \\
8 \cdot 50 \pm 1 \cdot 58 \\
2 \cdot 27 \pm 0.58\end{array}$ \\
\hline
\end{tabular}

Mean values \pm S.E.M. The number of observations are included in parentheses where they do not correspond with the number of rabbits in the group.

$\left(\mathrm{X}_{2}\right)$ within litters. The results from all rabbits in each group were pooled to obtain common regression coefficients which were tested for significance (Snedecor \& Cochran, 1967).

\section{Validation of technique}

In a preliminary test, a simultaneous injection of $50-\mu \mathrm{m}$ and $15-\mu \mathrm{m}$ microspheres in the 16-day pregnant rabbit gave calculated fetal placental to decidual blood flow ratios of 0.153 and 0.571 , respectively. Microspheres of $50 \mu \mathrm{m}$ diameter may have been selectively trapped in the decidua and thus may have led to an underestimate of fetal placental blood flow and an overestimate of decidual blood flow. In four rabbits, 16 to 28 days pregnant, the calculated mean percentage of the cardiac output distributed to the lungs was 
$1.8 \%$ and $4.9 \%$ for $50-\mu \mathrm{m}$ and $15-\mu \mathrm{m}$ microspheres, respectively. This result suggested that more of the $15-\mu \mathrm{m}$ microspheres passed through arterio-venous shunts to return to the right side of the heart and thence to the lungs. However, in the same four rabbits, the percentage of the cardiac output distributed to the fetal placenta and decidua collectively, the myometrium, the ovaries and the vagina showed no consistent difference when estimated from the $50-\mu \mathrm{m}$ and $15-\mu \mathrm{m}$ microspheres separately; thus, there was no evidence that a greater proportion of $15-\mu \mathrm{m}$ microspheres had escaped through arterio-venous shunts in these organs.

This point was further examined in five rabbits which were 0 to 30 days pregnant. Each rabbit was prepared for microsphere injection as described, except that its abdomen was opened and ligatures were positioned around the ovarian and uterine veins of one horn. The ligatures were tied, the vein midway between the ligatures was incised and the escaping blood was collected with cotton wool swabs for the next $60 \mathrm{sec}$. Immediately after tying the ligatures, microspheres were injected over a 30 -sec period. The mean percentage of microspheres passing through the uterus and ovaries without being trapped was $2.2 \%$ (range 0 to $5 \cdot 1 \%$ ), estimated by comparing the radioactivity of the venous effluent with the radioactivity of the uterine horn and ovary. The volume of venous blood collected was in the order of $80 \%$ of the expected volume (extrapolated from later microsphere experiments) that would have been drained by the veins encompassed by the ligatures. Even distribution of $15-\mu \mathrm{m}$ microspheres in the circulation was shown by the close correlation of cardiac output estimated from the brachial and femoral arterial samples, $r=0.975$, $\mathrm{n}=13$, and the correlation between blood flow ( $\mathrm{ml} / \mathrm{min}$ per $100 \mathrm{~g}$ tissue) to the left and right kidneys, $\mathrm{r}=0.957, \mathrm{n}=40$. One 16-day pregnant rabbit and two 24-day pregnant rabbits were given a simultaneous injection of $15-\mu \mathrm{m}$ $51 \mathrm{Cr}-$, and $15-\mu \mathrm{m} 85$ Sr-labelled microspheres. The correlation coefficients between fetal placental blood flows estimated from both isotopes were $r=0.934$, $\mathrm{n}=9 ; \mathrm{r}=0.981, \mathrm{n}=7$; and $\mathrm{r}=0.936, \mathrm{n}=10$, for the 16- and two 24-day pregnant rabbits, respectively. These results indicate that the number of microspheres used and their radioactivities were sufficient to provide repeatable estimates of the relatively small fetal placental blood flows.

\section{RESULTS}

General data on the rabbits involved in the experiment are given in Table 1. Fewer rabbits were included in the 24- and 28-day groups since information was already available on later stages of gestation (Duncan, 1969). All rabbits selected for microsphere injection, which survived the surgical procedures and proved to be pregnant, were included in the results. The percentage of the cardiac output distributed to the lungs was $5.00 \% \pm 0.57$ (S.E. of mean), $n=40$, rectal temperature was $38 \cdot 0^{\circ} \mathrm{C}$ (range 37.5 to $39 \cdot 0^{\circ} \mathrm{C}$ ).

Maternal weight appeared to increase from Day 16 to Day 28 but cardiac output was highly variable and showed no consistent change. There was no apparent change in arterial pressure, or blood $\mathrm{PO}_{2}, \mathrm{PCO}_{2}$, and pH levels during gestation. There was a considerable variation in the combined blood flow 
$(\mathrm{ml} / \mathrm{min})$ to the fetal placentae, decidua, myometrium and vagina between rabbits at each stage of gestation, although the distribution of blood flow between these organs appeared relatively uniform. This variation did not appear to be related to cardiac output, arterial pressure, blood $P_{\mathrm{O}_{2}}, P_{\mathrm{CO}_{2}}$ and $\mathrm{pH}$ values, or to the percentages of the cardiac output distributed to the heart, lungs and kidneys.

Five 4-day pregnant rabbits were used to determine the mean vaginal weight in $\mathrm{g}(1.41 \pm 0.14)$, vaginal blood flow in $\mathrm{ml} / \mathrm{min}(0.60 \pm 0.05)$, myometrial weight in $\mathrm{g}(16.9 \pm 1.9)$, and myometrial blood flow in $\mathrm{ml} / \mathrm{min}(8.4 \pm$

Table 2. Fetal weight, placental weight and placental blood-flow values at different stages of gestation in rabbits

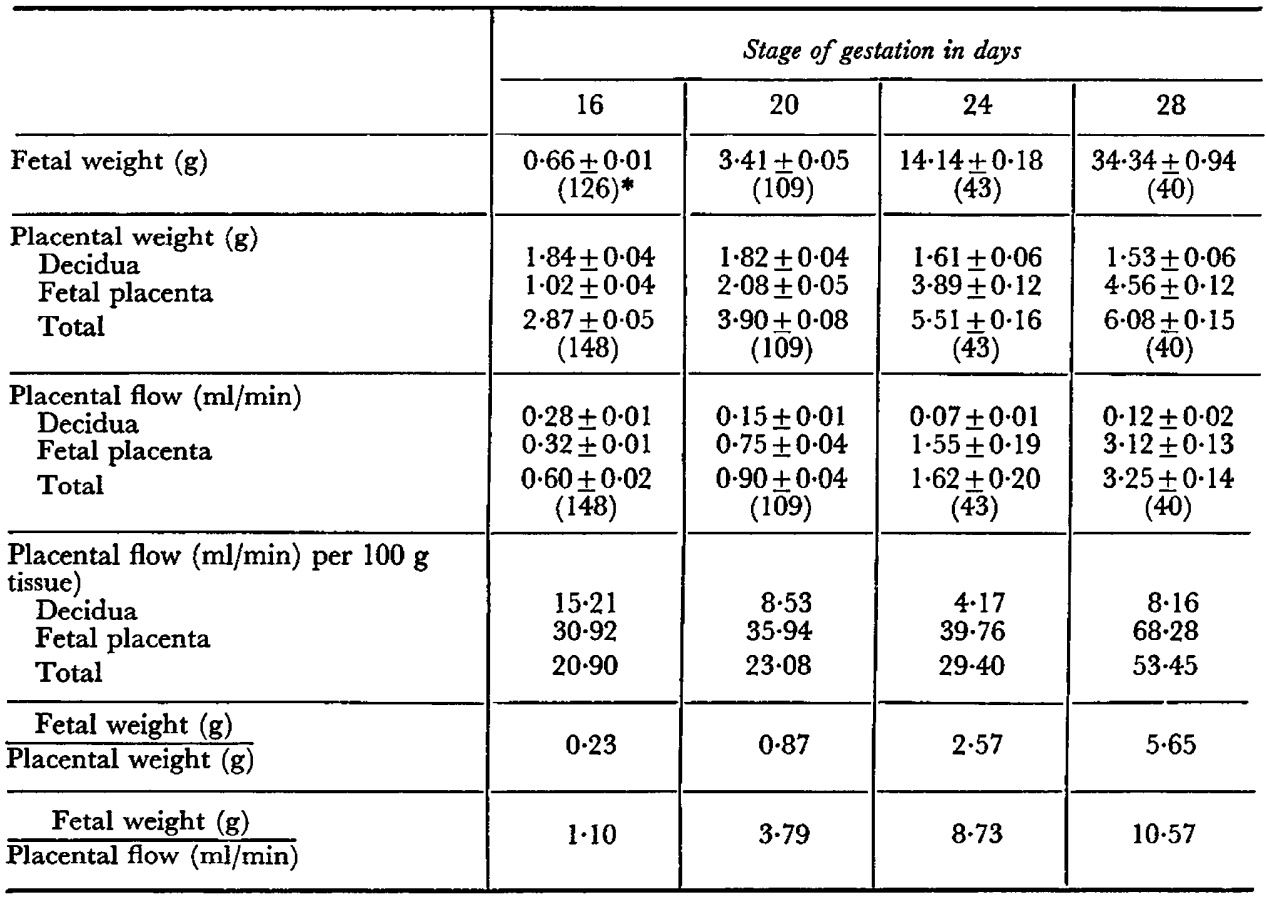

Mean values \pm S.E.M. were calculated from all conceptuses in each gestational age group. The number of observations contributing to the mean are shown in parentheses.

* Fetal weights were not obtained from two 16-day pregnant rabbits, thus reducing the number of observations in this group.

$0 \cdot 8$ ), for comparison with the 16- to 28-day values (Table 1 ). Vaginal weight steadily increased from Day 4 to Day 28 . Vaginal blood flow was more variable but also increased. Myometrial weight increased to Day 20 but thereafter no pattern was evident. Myometrial blood flow increased to Day 20 but was less thereafter.

The fetal placenta was bluntly dissected from the decidua and the decidua from the myometrium. This dissection became easier with advancing gestation as the zone of separation (Mossman, 1926) developed. Blood flow 
$(\mathrm{ml} / \mathrm{min}$ and $\mathrm{ml} / \mathrm{min} / 100 \mathrm{~g}$ tissue) decreased to the decidua but increased to the fetal placenta with advancing gestation (Table 2). The apparent distribution of blood flow may in part have reflected changes in the diameter of vessels running through the decidua to supply the fetal placenta. For this reason, and because accurate division of the fetal placenta and decidua was sometimes difficult, the two organs were pooled and have been referred to collectively as the placenta except where otherwise stated.

Fetal weight increased rapidly over the period of gestation examined. The rate of increase was reflected by the rate of increase in placental blood flow ( $\mathrm{ml} / \mathrm{min}$ and $\mathrm{ml} / \mathrm{min}$ per $100 \mathrm{~g}$ tissue; Table 2 and Text-fig. 1). The placental weight also increased from Day 16 to Day 28 but the rate of increase declined towards the latter end of gestation. The fetal weight/placental weight ratio increased more than twentyfold from Day 16 to Day 28 and the fetal weight/ placental flow ratio increased almost tenfold (Table 2).

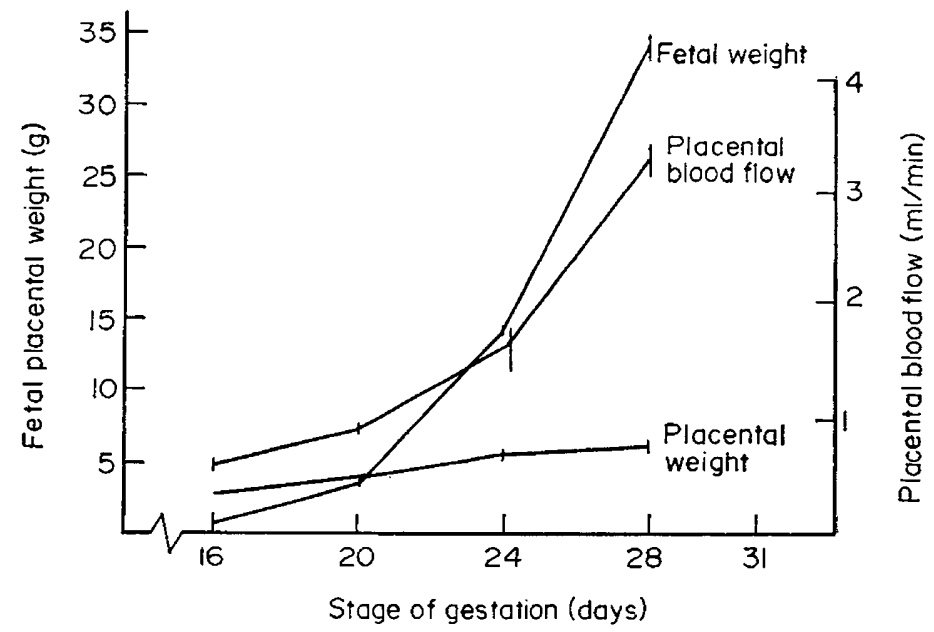

TEXT-FIG. 1. Fetal weight, placental weight and maternal placental blood flow at different stages of gestation. Vertical bars represent \pm S.E.M.

The mean fetal weight, placental weight and placental flow values and their ratios varied between rabbits at each stage of gestation. These variations did not appear to be related to the breed of rabbit, maternal weight or litter size. The multiple regression relationships of fetal weight $(\mathrm{Y})$ on placental weight $\left(\mathrm{X}_{1}\right)$ and placental flow $\left(\mathrm{X}_{2}\right)$ within litters were similar for all rabbits in each group; the common partial regression coefficients are given in Table 3. There was a positive linear partial regression coefficient of fetal weight on placental weight at all stages of gestation examined. These regression coefficients were all significant $(P<0.01)$ when the effect of placental flow was removed. The partial regression coefficient of fetal weight on placental flow differed both in magnitude and sign at different stages of gestation. It was negative on Day 16 $(P<0.05)$ but positive on Days $20(P<0.01), 24$ (not significant) and 28 $(P<0.01)$.

The conceptus adjacent to the ovary generally had greater fetal weight, 
Table 3. Multiple regression analysis of fetal weight on placental weight and placental blood flow at different stages of gestation in rabbits

\begin{tabular}{c|c|c|c|c}
\hline $\begin{array}{c}\text { Stage of } \\
\text { gestation } \\
\text { in days }\end{array}$ & $b_{1}$ & $b_{2}$ & $\begin{array}{c}\text { Significance of } \\
\text { placental weight } \\
\text { after removing } \\
\text { the effect of } \\
\text { placental blood } \\
\text { flow }\end{array}$ & $\begin{array}{c}\text { Significance of } \\
\text { placental blood } \\
\text { flow after } \\
\text { removing the } \\
\text { effect of } \\
\text { placental weight }\end{array}$ \\
\hline 16 & +0.086 & -0.097 & $P<0.01$ & $P<0.05$ \\
20 & +0.184 & +0.437 & $P<0.01$ & $P<0.01$ \\
24 & +0.721 & +0.452 & $P<0.01$ & Not sig. \\
28 & +3.052 & +1.158 & $P<0.01$ & $P<0.01$ \\
\hline
\end{tabular}

Fetal weight $(g)=a+b_{1}$ Placental weight $(g)$ $+b_{2}$ Placental flow ( $\left.\mathrm{ml} / \mathrm{min}\right)$

Table 4. Fetal weight, placental weight and placental blood flow values of the conceptus adjacent to the ovary and the mean values from all conceptuses in the horn at different stages of gestation in rabbits

\begin{tabular}{|c|c|c|c|c|c|c|c|c|c|c|c|c|}
\hline \multirow{2}{*}{$\begin{array}{l}\text { Stage of } \\
\text { gestation } \\
\text { in days }\end{array}$} & \multicolumn{4}{|c|}{ Fetal weight $(g)$} & \multicolumn{4}{|c|}{ Placental weight $(g)$} & \multicolumn{4}{|c|}{ Placental blood flow ( $\mathrm{ml} / \mathrm{min})$} \\
\hline & Ovarian & Mean & $n$ & $P<*$ & Ovarian & Mean & $n$ & $P<*$ & Ovarian & Mean & $n$ & $P<*$ \\
\hline $\begin{array}{l}16 \\
20 \\
24 \\
28\end{array}$ & $\begin{array}{r}0 \cdot 64 \\
3.38 \\
14 \cdot 53 \\
36 \cdot 27\end{array}$ & $\begin{array}{r}0 \cdot 64 \\
3 \cdot 34 \\
14 \cdot 33 \\
34 \cdot 45\end{array}$ & $\begin{array}{r}30 \\
21 \\
10 \\
9\end{array}$ & $\frac{\bar{z}}{0.05}$ & $\begin{array}{l}2 \cdot 95 \\
4 \cdot 31 \\
5 \cdot 97 \\
6 \cdot 18\end{array}$ & $\begin{array}{l}2.94 \\
3.97 \\
5.66 \\
5.96\end{array}$ & $\begin{array}{r}34 \\
21 \\
10 \\
9\end{array}$ & $\begin{array}{l}\overline{0} \\
0.02 \\
-05\end{array}$ & $\begin{array}{l}0.62 \\
1 \cdot 14 \\
1.93 \\
3.74\end{array}$ & $\begin{array}{l}0.59 \\
0.93 \\
1 \cdot 66 \\
3.28\end{array}$ & $\begin{array}{r}34 \\
21 \\
10 \\
9\end{array}$ & $\begin{array}{l}-\overline{0.001} \\
0.01 \\
0.01\end{array}$ \\
\hline
\end{tabular}

Ovarian-values for the conceptus adjacent to the ovary; mean-mean values from all conceptuses in the horn; $n$-the number of uterine horns, containing two or more conceptuses, included in the analysis.

* Significance of the difference between 'ovarian' and 'mean' values.

Table 5. Fetal weight/placental weight and fetal weight/ placental flow ratios for the conceptus adjacent to the ovary (ovarian) and the mean ratios for all conceptuses in the horn (mean) at different stages of gestation in rabbits

\begin{tabular}{|c|c|c|c|c|c|c|}
\hline \multirow{2}{*}{$\begin{array}{l}\text { Stage of } \\
\text { gestation } \\
\text { in days }\end{array}$} & \multicolumn{3}{|c|}{$\frac{\text { Fetal weight }(g)}{\text { Placental weight }(g)}$} & \multicolumn{3}{|c|}{ 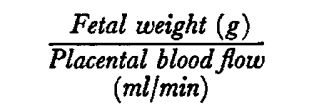 } \\
\hline & Ovarian & Mean & $P<*$ & Ovarian & Mean & $P<*$ \\
\hline $\begin{array}{l}16 \\
20 \\
24 \\
28\end{array}$ & $\begin{array}{l}0.22 \\
0 \cdot 78 \\
2 \cdot 43 \\
5 \cdot 87\end{array}$ & $\begin{array}{l}0.22 \\
0.84 \\
2.53 \\
5.78\end{array}$ & $\begin{array}{l}\overline{0.05} \\
-\end{array}$ & $\begin{array}{l}1.03 \\
2.96 \\
7 \cdot 53 \\
9 \cdot 70\end{array}$ & $\begin{array}{r}1.09 \\
3.59 \\
8.63 \\
10.50\end{array}$ & $\begin{array}{l}\overline{0.001} \\
0.05 \\
-\end{array}$ \\
\hline
\end{tabular}

Ovarian ratios for conceptus adjacent to the ovary; mean-mean ratios for all conceptuses in the horn.

* Significance of the difference between 'ovarian' and 'mean' ratios. 
placental weight and placental flow values than the average conceptus in the horn (Table 4). Placental flow appeared to be greater in the conceptus adjacent to the ovary as early as Day $16(0 \cdot 1>P>0.05)$, and placental weight as early as Day 20. A clear effect on fetal weight was not apparent until Day 28. The ratios of fetal weight/placental weight and fetal weight/placental flow were generally lower in the conceptus adjacent to the ovary than in the average conceptus in the horn (Table 5).

\section{DISCUSSION}

The mean vaginal, myometrial and placental weights and blood flow results at Day 28 of gestation agree with those reported earlier from this laboratory (Duncan, 1969). There was considerable variation in the combined blood flow to the reproductive organs between rabbits at each stage of gestation. This was unlikely to be due entirely to errors inherent in the microsphere technique, e.g. statistical variation in radioactivity measurements. Uterine blood flow may fluctuate from moment to moment in each rabbit and may vary between rabbits. There was variation in the physiological status of the rabbits at the time of microsphere injection although none of the physiological parameters examined appeared to correlate with blood flow rates to the reproductive organs. Although Duncan (1969) found that hypoxia caused a reduction in the placental flow, the lowest $\mathrm{Po}_{2}$ recorded in the present work was considerably above the hypoxic levels she examined.

Mossman (1926) and many subsequent authors refer to two placental components, the 'fetal placenta' which includes fetal villi and maternal tissues and the 'maternal placenta' which is composed almost entirely of maternal blood vessels and decidual tissue. In the present work, the term 'decidua' was used for the latter component, as seems appropriate from the comments of Amoroso (1952), and the two components were collectively referred to as the placenta. The decidua steadily decreased in weight from Day 16 to Day 28 of gestation. Blood flow $(\mathrm{ml} / \mathrm{min})$ to the decidua is comparable with that to the fetal placenta at Day 16 but falls rapidly later. The apparently high rate of decidual flow at Day 16 may be an overestimate due to technique but if the decidua were metabolically more active earlier in gestation (Reynolds, 1965), a higher rate of blood flow might be expected.

The maternal placental blood flow ( $\mathrm{ml} / \mathrm{min}$ per $100 \mathrm{~g}$ tissue) almost doubled between Days 24 and 28, although the mean arterial pressure showed little change. Clearly, the resistance to blood flow per unit weight of placental tissue is capable of considerable reduction during the latter part of gestation.

At all stages of gestation examined, there was a positive relationship between fetal weight and placental weight when the influence of placental flow was excluded. This might be expected later in gestation if fetal growth is limited by placental development. At Day 16, however, the mean fetal weight/placental weight ratio was only 0.23 so that the positive relationship between the two was more likely to have a genetic basis. The relationship of fetal weight to placental flow, when the influence of placental weight was excluded, was negative at Day 16 but positive at Days 20, 24 and 28. If the Day-16 result was not a 
chance effect, it might be explained in two ways. First, some factor may have affected fetal weight and placental flow in opposite directions. Second, some factor may have affected placental weight and placental flow in the same direction without affecting fetal weight. Amongst placentae of equal weight, those with higher blood flows would be heavier than expected genetically and would be associated with lighter fetuses.

The data relating to position in the uterine horn may fit the latter explanation. Duncan (1969) showed that in 27- to 29-day pregnant rabbits, fetal weight, placental weight and placental flow were greater in the conceptus at the ovarian end of each uterine horn than in conceptuses at intermediate or vaginal end positions. The present results confirm Duncan's findings and show that position in the horn affects placental flow by Day 20 (and perhaps even by Day 16), placental weight by Day 20 and fetal weight by Day 28. Generally, fetal weight/placental weight and fetal weight/placental flow ratios were lower in the conceptus adjacent to the ovary than in the average conceptus in the horn, indicating that position in the horn has a proportionately greater effect on placental flow and placental weight than on fetal weight. Position in the horn appears primarily to affect placental flow and placental weight and these factors in turn affect fetal weight; a direct but weak effect of position in the uterine horn on fetal weight cannot be discounted. The mechanism of the position in the horn effect has been debated. McLaren (1965) and others have suggested that the conceptus nearest the ovary is favoured haemodynamically in that it receives an arterial supply both from the ovarian and uterine arteries. However, ligation of the branches of the ovarian artery running to the uterus on Day 7 of gestation in the rabbit does not alter the position in the horn effect (N. W. Bruce, unpublished data). The ovary possibly has a localized influence on adjacent conceptuses.

The relative importance of genetic and environmental factors in the determination of fetal weight has long been in question. Observations that fetal weight is positively correlated to placental weight near term do not provide a definitive answer since this correlation could result from a common origin of the fetus and the fetal component of the placenta or from fetal growth being limited by the placenta. Alexander (1964) who retarded fetal growth in sheep by surgically removing some of the maternal caruncles before mating, and Wigglesworth (1964), who retarded fetal growth in rats by ligating uterine arteries near term, showed that fetal growth can be affected by extreme environmental conditions. Evidence that fetal growth is affected by the position in the uterine horn, by maternal age, parity and the number of young in the litter, provide a better indication of the influence of the environment on fetal growth under relatively normal conditions. The present study provides some indication of the stages in gestation at which genetic and environmental factors assert their influence on the rabbit fetus.

Earlier in gestation, the fetus is small relative to its placenta. However, a positive weight relationship between the two exists, at least by Day 16, and is probably determined genetically. Gates, Doyle \& Noyes (1961) reported that even in the blastocyst stage, where environmental factors are probably uniform, the rate of cell division of the conceptus is dependent on genotype. At the time 
of implantation, genetic dissimilarity between the mother and conceptus possibly influences the size of the placenta; Billington (1964) found the greater the dissimilarity the larger the placenta, although under certain conditions the reverse may also be true (Hetherington, 1971). Position in the uterine horn has also affected placental flow around Day 16 and placental weight soon after but not fetal weight, suggesting that fetal growth is not limited by placental weight or blood flow at these stages.

Later in gestation, the above factors are still operating but, in addition, fetal growth may to some extent be limited by available nutrients, blood gases or factors elaborated by the placenta, resulting in a dependent relationship of fetal weight on placental weight and placental flow. Finally, it is possible that fetal demand for nutrients may influence placental weight and blood flow, resulting in a dependent relationship in the opposite direction.

\section{ACKNOWLEDGMENTS}

We acknowledge with gratitude the advice of Dr G. S. Dawes and Dr P. Johnson and the technical assistance of Mrs J. McCairns. This work was supported by grants from the Medical Research Council and the Nuffield Committee for the Advancement of Medicine.

\section{REFERENCES}

Alexander, G. (1964) Studies on the placenta of the sheep (Ovis aries L.). Effect of surgical reduction in the number of caruncles. F. Reprod. Fert. 7, 307.

Amoroso, E. C. (1952) Placentation. In: Marshall's Physiology of Reproduction, Vol. 2. Ed. A. S. Parkes. Longmans Green, London.

Brzlington, W. D. (1964) Influence of immunological dissimilarity of mother and foetus on size of placenta in mice. Nature, Lond. 202, 317.

Duncan, S. L. B. (1969) The partition of uterine blood flow in the pregnant rabbit. F. Physiol., Lond. 204, 421.

Gates, A. H., Doyle, L. L. \& Noyes, R. W. (1961) A physiological basis for heterosis in hybrid mouse fetuses. (Abstract). Am. Zoologist, 1, 449.

Hetherington, G. M. (1971) The decidual cell reaction, placental weight, foetal weight and placental morphology in the mouse. 7. Reprod. Fert. 25, 417.

Mclaren, A. (1965) Genetic and environmental effects on foetal and placental growth in mice. 7. Reprod. Fert. 9, 79.

Mossman, H. W. (1926) The rabbit placenta and the problem of placental transmission. Am. F. Anat. $37,433$.

Reynolds, S. R. M. (1965) Physiology of the uterus, p. 245. Hafner, New York.

Snedecor, G. W. \& Cochran, W. G. (1967) Statistical methods, 6th edn, p. 381. Iowa State University Press, Ames.

Wigglesworth, J. S. (1964) Experimental growth retardation in the foetal rat. F. Path. Bact. 88, 1. 